\title{
39. UNA NUEVA LOCALIDAD DE NEPETA AMETHYSTINA VAR. ANTICARIA LADERO \& RIVAS GODAY EX UBERA \& VALDÉS.
}

\author{
Zoila DÍAZ LIFANTE y Raquel PARRA
}

Palabras clave. Nepeta, Lamiaceae, Península Ibérica, Andalucía, endemismo.

Key words. Nepeta, Lamiaceae, Iberian Peninsule, Andalucía, endemism.

Nepeta amethystina Poiret es una especie muy polimorfa propia de pedregales calizos del C, S y E de la Península Ibérica y del NO de África, de la que Ubera y Valdés (1983) distinguieron para la Península Ibérica tres subespecies, una de ellas con tres variedades. Las plantas del Torcal de Antequera, fueron separadas por Ubera y Valdés (l.c.: 40) como var. anticaria y han sido recientemente consideradas como subespecie por Cabezudo et al. (1991).

Desde su descripción, este taxón ha sido considerado endémico del Torcal de Antequera, de donde ha sido indicado por Ubera y Valdés (l.c.: 40), Gamarra y Fernández Casas (1989) y Cabezudo et al. (1.c.), y por Guerra (1982) y Smythies (1976) como N. amethystina Poiret y $N$. nepetella L., respectivamente.

Ha sido recientemente recolectada en la Sierra de las Cabras, sobre calizas (20.IV.1995, Leg. R. Parra, A. Rivero y B. Valdés, SEV) de donde cabía esperar su presencia, dada la proximidad de esta Sierra al Torcal de Antequera.

\section{BIBLIOGRAFÍA}

CABEZUDO, B., J.M. NIETO y T. NAVARRO 1991- Catálogo de las Labiadas (Labiatae) malacitanas (Málaga, España). Acta Bot. Malacitana, 16: 347-371.

GUERRA, J. -1982- Catálogo de la flora vascular del Torcal de Antequera (Málaga) Inst. Etud. Almer., Homenaje Rufino Sagredo: 105-119.
GAMARRA, R. y FERNÁNDEZ CASAS -1989Asientos para un atlas corológico occidental, Nepeta amethystina var. anticaria Ladero y Rivas Goday. Fontqueria, 23-62.

UBERA, J. y B. VALDÉS -1983- Revisión del género Nepeta (Labiatae) en la Península Ibérica. Lagascalia, 12: 3-80.

SMYTHIES, B.E. -1976- Contribution to the flora of Málaga. Acta. Bot. Malacitana, 2: 65-114.

Aceptado para su publicación en Junio de 1995

Dirección de los autores. Departamento de Biología Vegetal y Ecología. Facultad de Biología. Apdo. 1095. 41080, Sevilla. 